\title{
Project Plan for Vertical Lift Machine
}

\author{
G.F. Ellsworth
}

August 5, 2002

U.S. Department of Energy

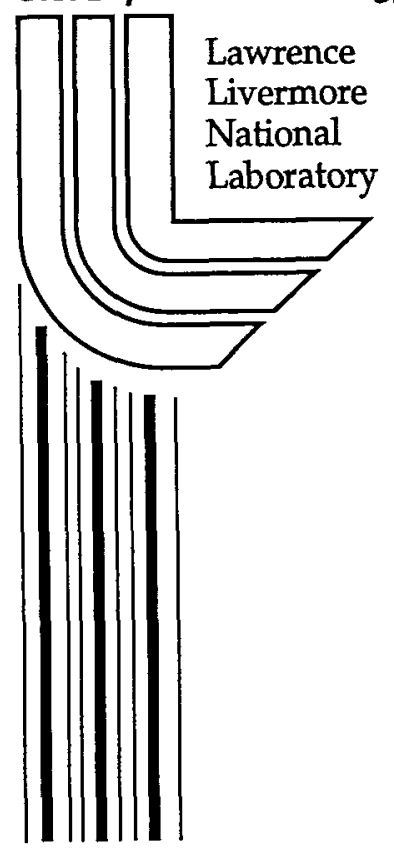




\section{DISCLAIMER}

This document was prepared as an account of work sponsored by an agency of the United States Government. Neither the United States Government nor the University of California nor any of their employees, makes any warranty, express or implied, or assumes any legal liability or responsibility for the accuracy, completeness, or usefulness of any information, apparatus, product, or process disclosed, or represents that its use would not infringe privately owned rights. Reference herein to any specific commercial product, process, or service by trade name, trademark, manufacturer, or otherwise, does not necessarily constitute or imply its endorsement, recommendation, or favoring by the United States Government or the University of California. The views and opinions of authors expressed herein do not necessarily state or reflect those of the United States Government or the University of California, and shall not be used for advertising or product endorsement purposes.

This work was performed under the auspices of the U. S. Department of Energy by the University of California, Lawrence Livermore National Laboratory under Contract No. W-7405-Eng-48.

This report has been reproduced directly from the best available copy.

Available electronically at http://www.doc.gov/bridge

Available for a processing fee to U.S. Department of Energy

And its contractors in paper from

U.S. Department of Energy

Office of Scientific and Technical Information

$$
\text { P.O. Box } 62
$$

Oak Ridge, TN 37831-0062

Telephone: (865) 576-8401

Facsimile: (865) 576-5728

E-mail: reports@adonis.osti.gov

Available for the sale to the public from

U.S. Department of Commerce

National Technical Information Service

5285 Port Royal Road

Springfield, VA 22161

Telephone: (800) 553-6847

Facsimile: (703) 605-6900

E-mail: orders@ntis.fedworld.gov

Online ordering: http://www.ntis.gov/ordering.htm

OR

Lawrence Livermore National Laboratory

Technical Information Department's Digital Library

http://www.llnl.gov/tid/Library.html 


\title{
Project Plan for Vertical Lift Machine (U)
}

\begin{abstract}
Prepared By:
G. Fred Ellsworth

Mechanical Engineer

DTED / B Adv. Development
\end{abstract}

August 2002

Reviewed By:

Don Carter

Group Leader

B Adv. Development
Doug Serpa

Project Lead / ADC

N Program

Approved By:

Mark Martinez

N Program Test Director 


\section{Introduction}

This document describes the Project Plan for the development and manufacture of a Vertical Lift Machine. It is assumed by this project plan that the Vertical Lift Machine will be developed, designed, manufactured, and tested by a qualified vendor. LLNL will retain review and approval authority for each step given in this project plan.

The Vertical Lift Machine is a single linear axis positioning device capable of lifting objects vertically at controlled rates and positioning them repeatedly at predetermined heights, in relation to other objects suspended from above, for high neutron multiplication experiments. Operation of the machine during the experiments is done remotely. The lift mechanism shall accommodate various platforms (tables) that support the objects to be raised. A frame will support additional subassemblies from above such that the lower subassembly can be raised close to and/or interface with those above. The structure must be stiff and motion of the table linear such that radial alignment is maintained (e.g. concentricity).

The safe position for the Vertical Lift Machine is the lift mechanism fully retracted with the subassemblies fully separated. The machine shall reside in this position when not in use. It must return to this safe condition from any position upon failure of power sources, open safety interlocks, or operator initiated SCRAM. The Vertical Lift Machine shall have the capability of return to the safe position with no externally applied power.

The Vertical Lift Machine shall have dual operator interfaces, one near the machine and another located in a remote control room. Conventional single key, key-lock switching shall be implemented to lock out the control interface not in use. The interface at the machine will be used for testing and "dry running" experimental setup(s) with inert subassemblies (i.e. Setup Mode). The remote interface shall provide full control and data recording capability (i.e. Assembly Mode).

The control system will be a combination of Programmable Logic Controller (PLC), or equivalent, and relay logic. The operator shall have the ability to adjust lift/lower velocity and position of the table. All measurements will be made as close to, and in line with, the axis of motion as practical. Measurement data, system parameter information, and interlock status shall be displayed. 


\section{Functional Requirements}

\section{Mechanical}

- Lift force (upward) of $2000 \mathrm{lb}$.

- Tolerate off-axis loading of $800 \mathrm{lb}$ at $3 \mathrm{ft}$ from lift axis.

- Provide possible disassembly (downward) force of 10,000 lb.

- Lift range of 36 in. (min.)

- Positioning accuracy within 0.010 in.

- Positioning repeatability within 0.001 in.

- Positioning velocity range of 0.6 to $15 \mathrm{in} / \mathrm{min}$.

- SCRAM acceleration of $1 \mathrm{~g}$ downward for at least 1 in. of initial travel.

- Deceleration to safe position controlled and not to exceed $1 \mathrm{~g}$.

- Straightness of travel within 0.020 in. through full range. (Two directions)

- Angular motion about vertical axis within 1 degree through full lift range.

- Attachment points for upper fixtures supporting up to $2000 \mathrm{lb}$.

- Smooth surfaces and covered plumbing/electrical. (For cleaning)

- Design for return to safe position with no externally applied power.

- Geometrically stable. (no seismic anchoring will be allowed)

- All machine subassemblies easily detachable and mobile using wheels and/or forklift lift-points.

- Crane lift points provided on upper fixture and base.

- Max assembled height of $10 \mathrm{ft}$.

- Subassemblies must fit through entry door $7 \mathrm{ft} \times 7 \mathrm{ft}$ (height / width).

- Industry standard material finishes (e.g. paint, powder coat, etc.) are acceptable.

- Fluid for fluid power systems must be approved by LLNL. (Nonflammable)

\section{Electrical / Control}

- Remote and local control consoles, at the machine and in the remote control room. Only one control location active at a time.

- Control using Programmable Logic Controller (PLC), or equivalent, and relay logic. Progressive enable logic is preferred by LLNL.

- Operating mode selection (Setup Mode, Assembly Mode and Off Mode) by means of key-lock switches. One switch at the machine and one in the remote control room. Single key operation.

- LCD (or equivalent) control screens to display position / velocity / acceleration, monitor interlock signals, and show functioning of machine systems including set-point values.

- Data recording system to include changes in lift location, all system parameters, and interlock conditions as a function of time.

- SCRAM pushbuttons located at Lift Machine and remote control room to "safe" the system by disconnecting operation control and energizing shutdown hydraulic valves and/or motors. 
- Monitor internal interlock signals such as fluid system pressure(s), electrical power, and/or proper control function.

- Accept external interlock signal(s) (e.g. temperature, entry door, etc.).

- Display status for interlock and system signals.

- Control system self-tests machine and components automatically.

- Closed-loop control of lift position / velocity / acceleration with operator input by means of rotary control knobs and rotary mode switches (real or virtual).

- Soft landing control during SCRAM.

- Electrical components within one foot of the lift table should survive $20,000 \mathrm{Rad}$ exposure. (Rare event occurrence.)

- UL approved components and NEMA construction.

- UL approved plug ends for connection to facility power.

- Power outages to result in controlled shutdown and safe lowering of lift mechanism.

- Power glitches less than 5 seconds to cause no disturbance to control system or machine operation.

- Allow for expansion of system to accept future valve and/or motor control and encoders.

Available items

Although the following items will be available in the experimental area, the Vertical Lift Machine shall be designed to be a self-contained device with minimal reliance and draw on the facility. Unexpected loss of Power, Compressed Air and/or Vacuum shall not lead to an unsafe condition.

- Available “industrial” power: 208/120 Vac @ 30 Amps, 3 phase Y

- Available "common" power: 120 Vac GFCI @ 20 Amps

- Available compressed air:

8 CFM@100 psig

- Available vacuum:

10 CFM@18-in. Hg

\section{Design Requirements}

\section{Safety Factor(s):}

Current LLNL Mechanical Engineering Design Safety Standards require a general purpose safety factor of three (3) on yield of all mechanical components and interfaces under design loading. Factor of safety on ultimate strength must be four (4) or greater.

High Pressure Safety at LLNL requires that all fluid power components be shown to have a factor of safety of four (4) or greater. Remote pressure testing by qualified LLNL personnel will be required for manned use of a fluid power system. Fluid power systems include the use of compressed air for pneumatic devices. Use of compressed air at the full-line supply pressure of 100 psig is preferred. 
Rare Events require a minimum safety factor of one (1) on yield and/or 1.25 on ultimate strength. Seismic events are considered Rare Events for design at LLNL. Hardware must be shown to remain stable under combination seismic loads.

Calculations:

Closed form analytical calculations are preferred by LLNL whenever practical. Finite Element Analysis (FEA) may be allowed, however, sufficient closed form checks of the FEA set-up and boundary conditions will be required.

\section{Concept Development}

It is the desire of LLNL to procure a Vertical Lift Machine that is both robust and "state of the art." Qualified vendors will demonstrate competency in the manufacture of quality positioning and assembly hardware. Fresh perspective from vendors will be seriously considered. Concepts developed by qualified vendors will be reviewed by LLNL for safety, operability, and ease of experimental use. A vendor representative authorized to defend and/or modify the vendor concept must be present, and may be asked to formally participate, at the LLNL conceptual design review.

Conceptual design deliverables shall include:

- Functional Flow Diagrams describing how subsystems interact to meet the functional requirements.

- Subsystem block diagram(s) defining interfaces for system separation into modular units for mobility.

- Envelope Drawings showing external dimensions, interface connections, electrical requirements, and approximate subsystem weights.

- Control system architecture diagrams describing in sufficient detail the overall function of the machine and the response to subsystem failure.

- Use of facility resource estimates, detailed by type. (e.g. electrical use)

- Target costs for detailed design and manufacture of the machine.

\section{Vendor Design}

Following review and approval of the fully developed vendor concept, the vendor will commence with a detailed design of the Vertical Lift Machine. The completed detail design of the Vertical Lift Machine will be subject to formal LLNL design review. LLNL will retain the right to review and approve all aspects of the design of the Vertical Lift Machine. A vendor representative knowledgeable in the design of the Vertical Lift Machine must be present at the LLNL final design review to address design questions and any vendor related action items.

Final design review deliverables shall include:

- Assembly drawings that show all component parts properly assembled and shall show outline dimensions. Detailed design drawings showing all manufacturing and inspection information. (Pro/ $\mathrm{E}^{\mathrm{TM}}$ format is preferred by LLNL.) 
- Detailed interface drawings showing how each major assembly quick disconnects for machine removal to alternate experimental locations.

- Electrical drawings including both schematics and wiring diagrams.

- Hydraulic system diagram(s) showing overall component placement and interconnection details. Hydraulic circuit diagram(s) showing all components and their interaction.

- Final logic diagrams showing the function and interaction of each logic element in the system.

- Proposed part list that includes manufacturer's name and part number for all parts not manufactured directly by the vendor.

- Software design documentation establishing the software and hardware requirements and the coding baseline. Include algorithms, data structures, interface definitions and I/O formats. (Use of LabView ${ }^{\mathrm{TM}}$ is preferred by LLNL.)

- Load analysis on facility resources by type. (e.g. electrical use, compressed air, vacuum, etc.)

\section{Construction}

Manufacture of the Vertical Lift Machine will follow approval of the vendor design. LLNL personnel assigned to the Vertical Lift Machine will follow construction as they are expected to become intimately familiar with the design and construction of the machine. At the completion of construction, LLNL engineers will become the first line of support for the Vertical Lift Machine.

Integral to the construction process shall be the development of thorough documentation. Assembly procedures, construction techniques, material selection and qualification, component references, and any other construction related documentation shall be required from the vendor.

\section{Acceptance Testing}

Every functionally significant aspect of the Vertical Lift Machine will require acceptance testing to validate performance. Results of acceptance testing will also serve as a baseline for future evaluation of machine performance (i.e. troubleshooting). Clear and complete documentation of the testing procedures, parameters, instrument set-up and results are required from the vendor.

Procedures for acceptance testing will be developed in cooperation with the vendor and will require LLNL approval. Acceptance criteria will be integral in the development of the concepts, design, and cost requirements.

Acceptance testing will include the following at a minimum:

Lift capacity

Lift range (stroke)

Straightness of travel 
Positioning accuracy

Positioning repeatability

Angular motion

Rate(s) of lift travel

SCRAM function(s)

Loss of power return

Safety interlock function(s)

Base alignment for upper fixture(s)

Upper fixture(s) capacity

Qualified LLNL personnel chosen by the project lead will witness all acceptance testing. It is expected that acceptance testing will be performed at the vendor using test equipment supplied by the vendor.

Following successful acceptance testing, the vendor shall conduct operator training for LLNL personnel. Training materials and operation documentation will be the responsibility of the vendor. Training must include general operation of the Vertical Lift Machine and the response of the machine to credible failure scenarios.

Following acceptance of the testing results, the Vertical Lift Machine will be packaged for shipping and shipped by the vendor to the experimental location.

\section{Installation Procedures}

LLNL engineers assigned to the Vertical Lift Machine will be responsible for the installation and pre-experimental testing of the machine. The vendor will be expected to provide installation / assembly procedures and any necessary training. The vendor will be expected to have qualified personnel available for installation support, which may include providing personnel to assist in assembly, should it be required by LLNL.

The experimental location for the Vertical Lift Machine is a facility at the Nevada Test Site (NTS). Documentation required by the receiving facility (e.g. MESN(s)) will be the responsibility of the LLNL personnel assigned to the machine. 